Relations industrielles

Industrial Relations

\title{
The Principle of Industrial Relations, by A.E.C. Haro, Macmillan Company of Canada Limited, 70 Bond Street, Toronto 2, $1958145 \mathrm{pp}$.
}

\section{Gérard Dion}

Volume 14, numéro 4, octobre 1959

URI : https://id.erudit.org/iderudit/1022142ar

DOI : https://doi.org/10.7202/1022142ar

Aller au sommaire du numéro

Éditeur(s)

Département des relations industrielles de l’Université Laval

ISSN

0034-379X (imprimé)

1703-8138 (numérique)

Découvrir la revue

Citer ce compte rendu

Dion, G. (1959). Compte rendu de [The Principle of Industrial Relations, by A.E.C. Haro, Macmillan Company of Canada Limited, 70 Bond Street, Toronto 2, 1958 145 pp.] Relations industrielles / Industrial Relations, 14(4), 622-622.

https://doi.org/10.7202/1022142ar

Tous droits réservés (C Département des relations industrielles de l’Université Laval, 1959
Ce document est protégé par la loi sur le droit d'auteur. L'utilisation des services d'Érudit (y compris la reproduction) est assujettie à sa politique d'utilisation que vous pouvez consulter en ligne.

https://apropos.erudit.org/fr/usagers/politique-dutilisation/ 
Beaucoup d'ouvrages et d'articles spécialisés sont publiés. La littérature est abondante, si abondante, qu'à moins d'être un spécialiste on ne peut la parcourir dans son entier.

C'est le mérite de la collection « Reference Shelf $\gg$ de présenter aux lecteurs une anthologie des meilleurs articles écrits sur un sujet donné. Dans cet ouvrage portant sur le mouvement ouvrier américain, on a essayé de mettre à la portée des lecteurs les différents aspects du développement actuel que prend le syndicalisme aux Etats-Unis. - La première partie est consacrée à un rappel historique. La seconde décrit la position du syndicalisme à la suite de la fusion de l'AFL avec le CIO. La troisième discute l'activité syndicale et ses objectifs dans le contexte politique et économique actuel. Enfin deux problèmes particuliers sont abordés: les lois du «droit au travail 》 et la corruption syndicale. Chacune de ces parties est présentée par une brève introduction de l'éditeur.

Encore une fois, les éditeurs de cette anthologie auront grandement rendu service à tous leurs lecteurs en mettant à la portée de leur main un ouvrage qui les dispensera de recourir inutilement à beaucoup d'autres publications.

$$
\text { G. D. }
$$

The Principle of Iudustrial Relations, by A.E.C. Haro, Macmillan Company of Canada Limited, 70 Bond Street, Toronto 2, $1958145 \mathrm{pp}$.

Voici un petit livre bien fait, sans appareil scientifique. Il est, le fruit d'une longue expérience et d'une connaissance approfondie des problèmes de relations du travail. Le titre, cependant, ne nous apparait pas trop approprié car il est question surtout du malaise industriel.

L'auteur, professeur à l'Université Leeds en Angleterre, reprend ici l'exposé d'ordre général qui introduisait son rapport préparé sur les relations industrielles en Nouvelle-Zélande. Après une introduction où il place les problèmes de relations industrielles dans le cadre plus vaste de la société, l'auteur expose les caractéristiques du travail industriel et la situation du travailleur dans ce système de production.
Puis il analyse longuement les causes du malaise industriel et montre quelle peut être la contribution de l'état, des syndicats ouvriers et des employeurs pour y remédier.

Pour ceux qui ne sont pas au courant de ces problèmes, cet ouvrage peut servir d'une excellente initiation.

\section{GÉrard Dion}

\section{Social Principles and Economic Life,} by Rev. John F. Cronin, S.S. Ph. D. The Bruce Publishing Company, Milwaukee, 1959,436 pp. $\$ 6.50$

L'auteur avait publié en 1950 un ouvrage Catholic Social Principles qui a connu une large diffusion et qui a été utilisé comme manuel de classe dans les écoles. Les changements dans les conditions économiques et sociales, les abondantes interventions du pape Pie XII dans ce domaine ont amené l'auteur à présenter une nouvelle édition. Comme cette revision, même si elle a été faite en gardant les mêmes perspectives, a graduellement entrainé l'auteur à apporter des modifications considérables, oelui-ci a décidé de donner un nouveau titre à son ouvrage.

L'auteur offre ici une exposition et une explication des principes sociaux chrétiens en tenant compte du contexte américain. Si l'enseignement social de l'Eglise est fondamentalement de la morale naturelle, de la théologie, les jugements prudentiels doivent tenir compte des sciences économiques et sociales.

Cet ouvrage est divisé en trois parties. La première envisage les problèmes sociaux de base, la question sociale, l'Eglise et le problème social, l'homme et la vie économique, les vertus sociales, les courants de philosophie sociale, le communisme, l'ordre social idéal. Le seconde partie est consacrée à l'application des principes sociaux aux principales institutions économicosociales: droits et devoirs du capital; relations capital- travail; le salaire vital et le plein emploi; les problèmes économiques de la famille; la propriété, l'Etat et la vie économique. Enfin la dernière partie envisage certains problèmes particuliers: la politique internationale et la vie économique; la dis- 